Please do not remove this page

RMIT

UNIVERSITY

\title{
Improving the fracture resistance of sandwich composite T-joints by z-pinning
}

Nanayakkara, Asintha; Feih, Stefanie; Mouritz, Adrian

https://researchrepository.rmit.edu.au/esploro/outputs/9921862201801341/filesAndLinks?institution=61RMIT_INST\&\&index=null

Nanayakkara, A., Feih, S., \& Mouritz, A. (2013). Improving the fracture resistance of sandwich composite T-joints by z-pinning. Composite Structures, 96, 207-215.

https://doi.org/10.1016/j.compstruct.2012.09.029

Published Version: https://doi.org/10.1016/j.compstruct.2012.09.029

Repository homepage: https://researchrepository.rmit.edu.au

(C) 2012 Elsevier Ltd. All rights reserved.

Downloaded On 2023/04/27 00:33:57 +1000

Please do not remove this page 
Thank you for downloading this document from the RMIT Research Repository.

The RMIT Research Repository is an open access database showcasing the research outputs of RMIT University researchers.

RMIT Research Repository: http://researchbank.rmit.edu.au/

\section{Citation:}

Nanayakkara, A, Feih, S and Mouritz, A 2013, 'Improving the fracture resistance of

sandwich composite T-joints by z-pinning', Composite Structures , vol. 96, pp. 207-215.

See this record in the RMIT Research Repository at:

http://researchbank.rmit.edu.au/view/rmit:18110

Version: Accepted Manuscript

Copyright Statement: ㄷ 2012 Elsevier

Link to Published Version:

http://dx.doi.org/10.1016/j.compstruct.2012.09.029 


\title{
IMPROVING THE FRACTURE RESISTANCE OF SANDWICH COMPOSITE T-JOINTS BY Z-PINNING
}

\author{
A. Nanayakkara, S. Feih and A.P. Mouritz* \\ School of Aerospace, Mechanical \& Manufacturing Engineering, RMIT University, \\ GPO Box 2476, Melbourne, Victoria, Australia 3000
}

\begin{abstract}
This paper presents an experimental and analytical study into the strengthening and toughening of sandwich composite joints by z-pinning. Cleats connecting the vertical stiffener and horizontal base panel to T-shaped sandwich joints were reinforced in the through-thickness direction with pins. Tensile (stiffener pull-off) tests revealed that pinning increased the ultimate fracture load and fracture energy by resisting crack growth along the cleat-skin and skin-core interfaces, which were the weakest points in the unpinned joint. The peak fracture load and fracture energy increased with the volume content of z-pins. The strengthening and toughening effect of the pins was analysed using multiple pin pull-out tests performed on the sandwich composite material. It is shown that elastic deformation, debonding and pull-out of the pins from the face skins to the sandwich composite is the primary toughening mechanism of the pinned T-joints. The pin pull-out process which is the cause for the high strengthening and toughening of the T-joints is analysed using bridging traction modelling.
\end{abstract}

\footnotetext{
- Corresponding author: A.P. Mouritz

Tel: +61 399256269

e-mail: adrian.mouritz@rmit.edu.au
} 


\section{INTRODUCTION}

The joints connecting sections of sandwich panels are often the weakest link in sandwich composite structures. Various designs are used to maximise the fracture load limit of sandwich joints, including T-shaped joints, U-channel joints and other bonded fillet designs as well as bolted connections [e.g. 1-4]. Sandwich joints are susceptible to interfacial cracking along the skin-stiffener connection and the face skin/core region within the sandwich material due to their low out-of-plane strength and fracture toughness properties. The usual method of increasing the interfacial fracture toughness is to use high-strength adhesive along the joint connections. An alternate approach that may be effective in the strengthening and toughening of sandwich joints is through-the-thickness reinforcement using z-pins, although this method has not been previously investigated.

Z-pins are thin fibrous composite or metal rods that are inserted through-the-thickness of composite materials to promote high interlaminar fracture toughness. Numerous research studies have shown that pinning is effective at increasing the structural properties (including the fracture load and toughness) of T-joints, L-shaped joints, stiffened panels and lap joints made of composite laminates [5-14]. Pinning can also promote large increases in the fatigue life of laminate joints by resisting interfacial cracking between the adherends. For example, Koh et al. [10] recently reported that the ultimate load and fracture energy of carbon/epoxy Tjoints were increased respectively by up to $75 \%$ and over $600 \%$ with pinning. Chang et al. [7] measured a $40 \%$ increase in the fatigue strength of single lap joints when reinforced with pins. The properties were improved by the pins generating bridging traction loads which resist large-scale crack growth in the joints. 
While the strengthening and toughening of laminate joints by pinning has been proven, it is not known whether pinning will significantly increase the fracture resistance of sandwich composite joints. The strengthening and toughening provided by pins is reliant on the formation of bridging traction loads along cracks within the joint [6-14], and it is not known whether the bridging response is different for sandwich composites due to the foam core and the skin-core interfaces. The aim of this study is therefore to experimentally determine the effect of pinning on the structural properties and strengthening mechanics of sandwich composite joints. The joint type examined was a traditional fillet T-joint, which is one of the most common designs for joining sandwich composite panels. The joint was made with thin face skins of carbon fibre/epoxy laminate and a thick core of polymer foam, and this sandwich material is used in aircraft structures. The effect of increasing the volume content of pins on the ultimate fracture load and fracture energy of the sandwich composite joint was determined. Also, the effect of pinning on the development of damage and final fracture of the T-joint was assessed. The strengthening and toughening mechanics of the sandwich joint were analytically and experimentally studied using pin pull-out tests which provide information on the bridging traction behaviour of pins in sandwich materials.

\section{SANDWICH JOINTS AND EXPERIMENTAL METHODOLOGY}

\subsection{Fabrication of Sandwich T-Joints}

The design and geometry of the sandwich T-shaped joint used to assess the effectiveness of pins to increase the structural and fracture properties is shown in figure 1 . The joint was constructed using two flat sandwich composite panels which formed the base and stiffener, and they were joined using two L-shaped laminate cleats. The cleats and face skins to the sandwich composite were made using eight plies of T700 carbon/epoxy prepreg (VTM264) arranged in a cross-ply stacking sequence $[0 / 90 / 0 / 90]_{s}$. The core material used in the base and 
stiffener panels was a closed-cell polymethacrylimid (PMI) foam (Rohacell Type 71RIST supplied by Evonik GmbH). The local regions where the cleats, stiffener panel and base panel connect were filled with unidirectional prepreg to avoid the formation of weak resin-rich zones. The cleats were bonded directly on to the stiffener panel and base panel by co-curing inside an autoclave operated at an overpressure of $276 \mathrm{kPa}$ and temperature of $120^{\circ} \mathrm{C}$ for one hour. Adhesive was not used to aid the bonding of the joint components.

Before curing, the horizontal section of the cleats was joined to the base panel by z-pinning using $0.28 \mathrm{~mm}$ diameter rods of pultruded T300 carbon/bismaleimide (Albany Engineered Composites Pty Ltd.). The cleat/base panel connection was reinforced with a low (0.5\%) or high (2\%) volume content of pins. The pins were inserted using the Ultrasonically Assisted Z-Fiber (UAZ) process, which basically involved driving the pins from a foam carrier preform into the uncured sandwich joint using high frequency (20 kHz) ultrasonic vibrations [15]. The pins were inserted through the entire thickness of the horizontal section of the cleat and the sandwich base panel, as illustrated in figure 1a. The leading tip of the pin, which was forced into the sandwich material, was chamfered to ease the insertion process whereas the trailing end of the pin was blunt, as shown in figure 2. The pins were arranged in a square grid pattern with the rows aligned along and across the cleat-base panel sections. The pins were spaced $3.5 \mathrm{~mm}$ and $1.75 \mathrm{~mm}$ apart for the low and high density pinning, respectively. In addition to T-joint specimens being made with the low or high amounts of pin reinforcement, unmodified specimens were also produced without pins as the control joint. The geometry and fabrication of the unpinned T-joint was identical to the pinned joints, with the only difference being the absence of pins. 
Many of the pins in the fully cured sandwich material were slightly offset from the orthogonal direction. Figure 3 presents an X-ray tomography image of the sandwich composite showing that the pins were inclined at various angles. The inclination angle of the pins varied over a range up to $12^{\circ}$ (Figure 3b). Based on the work by Chang et al. [16] for carbon/epoxy laminates that were pinned with the same UAZ process used here for the sandwich joints, it appears that the cutting off of the excess pin length and consolidation of the material within the autoclave are the main causes for the pins being inclined at various angles from the orthogonal direction.

\subsection{Structural Fracture Testing of Sandwich Joints}

The structural properties of the unpinned and pinned sandwich T-joints were measured by applying a pull-off load parallel with the stiffener (as indicated by the arrow in Figure 1) until final fracture. The ends of the base panel were rigidly clamped, with an unrestrained length of $150 \mathrm{~mm}$. A tensile force was applied to the stiffener end using a $50 \mathrm{kN}$ Instron loading machine operated at a constant displacement rate of $1 \mathrm{~mm} / \mathrm{min}$. From these tests the peak fracture load and fracture energy of the T-joints were measured. Six specimens of each type of T-joint were tested under identical conditions to assess the variability in the fracture properties.

\subsection{Pin Pull-Out Tests on Sandwich Composites}

Multiple pin pull-out tests were performed on flat panels of the sandwich composite material, as shown schematically in figure 4 . These tests were performed to determine the bridging traction load and traction fracture energy generated by a single pin under mode I loading, which is similar (but not identical) to the tensile loading on the pins along the cleat-base panel connection in the structural pull-off tests performed on the sandwich joints. As 
explained later, the pins in the joint experience mixed mode I/II interlaminar loading as opposed to pure mode I interlaminar loading on the pin that occurs in the pull-out test.

The pin pull-out test specimen (measuring $40 \mathrm{~mm}$ x $20 \mathrm{~mm}$ ) was reinforced with the same pins used in the joints. The entire area of the specimen was reinforced with about 80 or 260 pins, which is equivalent to the low and high volume pin contents, respectively. A tensile load was applied normal to the face skins of the sandwich composite at a displacement rate of $1 \mathrm{~mm} / \mathrm{min}$ to final failure. Pull-out tabs were bonded to the face skins of the specimen using a high strength epoxy adhesive (Araldite 420). The measured load was divided by the total number of pins in the sandwich sample to determine the average traction load generated by each pin. Three samples of the sandwich materials reinforced with the low and high pin contents were tested under identical conditions.

\section{RESULTS AND DISCUSSION}

\subsection{Structural Properties and Fracture of Pinned Sandwich Joints}

Figure 5 presents typical applied load-displacement curves for the unpinned and pinned sandwich joints measured in the tensile pull-off test. The curves are characterised by multiple load spikes caused by progressive fracture of the joints, although the loads sustained by the pinned joints were higher over most of the displacement range up to final failure (which is the complete failure of the joint occurring at the displacement of $45-50 \mathrm{~mm}$ ). Using these curves, the peak fracture load and fracture energy of the joints were determined, and the values are given in figure 6 . The fracture load was the maximum load sustained by the joint before final failure, and the fracture energy was determined from the total area under the curve. It was found that increasing the pin content increased the peak fracture load and fracture energy of the joints, and at the highest pin content these properties were raised by an average of 20\% 
and over $50 \%$, respectively. There is significant scatter in the measured property values, and the likely cause of this variability is discussed later.

Pinning also changed the damage and fracture mode of the joint. The unpinned joint initially failed by core cracking within the stiffener panel which was immediately followed by skincore debonding in the base panel, and final fracture occurred by delamination cracking along the bonded interface between the cleat and base panel. This sequence of damage events with increasing displacement is shown in figure 7. The pinned joints also initially failed by core cracking in the stiffener (which was not pinned), however skin-core debonding was arrested by the pins and cleat fracture did not occur. This represents a major change in the fracture behaviour of the joint due to pinning. The pinned joints fractured by skin rupture in the base panel, as shown in figure 8. The strengthening and toughening mechanics responsible for the increases to the peak fracture load and fracture energy and the change to the fracture mode of the pinned joints were investigated by pin pull-out tests on the sandwich composite.

\subsection{Bridging Traction Properties of Pins in Sandwich Composites}

Figure 9 presents three examples of traction load-crack opening displacement (extension) curves for a single pin within the sandwich composite under through-thickness tensile loading. The curves were measured using the multiple pin sandwich specimens illustrated in figure 4, with the traction load being the average force acting on a single pin (which is the total force divided by the number of pins in the specimen). The through-thickness tensile load applied on the pin pull-out specimens was similar to that experienced by the pins in the sandwich joints, although the pins along the cleat/skin bond-line also experienced an interlaminar shear stress induced by bending of the skin panel (i.e. mixed mode I/II loading). The traction load curves in figure 9 are similar in profile to those measured for laminates [17- 
19], and characterised by an initial elastic response of the pin followed by a sudden and large load drop, and then a more gradual load drop with increasing displacement to final failure. The initial increase in the traction load is due to elastic stretching of the pin, the large load drop is due to debonding of the pin from the sandwich material, and the gradual load drop is due to the loss in friction force as the pin is pulled out from the material. While the profiles for the traction load-extension curves were similar for the pinned sandwich materials, there were large differences between nominally identical specimens and the cause of this is discussed later.

The load reaction of a single pin within the sandwich composite under an applied tensile load during the elastic phase (i.e. before debonding and pull-out) is shown schematically in figure 10. The traction load generated by a pin within a sandwich composite can be estimated using a modified form of the mode I bridging traction laws for pinned laminates [20,21]. The elastic traction load generated by a pin up to the ultimate load point is due mainly to interfacial shear stress transfer across the bonded pin-sandwich composite interface, which includes the two face skins and core. The elastic load $(P)$ is a function of the crack opening extension $(\delta)$ up to the ultimate load point $\left(P_{\max }\right)$ according to:

$$
P_{\text {elastic }}(\delta(h))=2\left(\tau_{s} \pi d_{p} h_{s}\right)+\left(\tau_{c} \pi d_{p} h_{c}\right) \quad P_{\text {elastic }} \leq P_{\max }
$$

The first and second terms represent the elastic traction loads generated by the interfacial shear stress between the pin and the two face skins and the pin and core, respectively. $\tau_{s}$ is the interfacial shear strength between the pin and face skin, $\tau_{c}$ is the interfacial shear strength between the pin and core, $d_{p}$ is the pin diameter, and $h_{s}$ and $h_{c}$ are the original length portions of the pin in the skins and core. It is assumed with equation 1 that the pin is perfectly 
orthogonal and fully bonded to the face skins and core. It is also assumed the residual cure stresses within the face skins do not alter the interfacial shear strength.

The interfacial shear stress generated at the pin-face skin interface is much greater than the shear strength of the pin-core interface $\left(\tau_{s}>>\tau_{c}\right)$. This is because the contact area between the pin and laminate skins is much greater than the area between the pin and core due to the porous cellular structure of the polymer foam. Therefore equation 1 reduces to:

$$
P_{\text {elastic }}(\delta(h)) \approx 2 . \tau_{s} \pi d_{p} h_{s}
$$

The displacement is a function of the skin thickness $\left(h_{s}\right)$ according to:

$$
\delta\left(h_{s}\right)=\left[h-\frac{h_{s}}{r} \ln \left(\frac{h \times r}{h_{s}}+1\right)\right]\left[1+\frac{h \times r}{h_{s}}\right]
$$

where $r$ is the tensile extensibility ratio of the pin, which equals [20]:

$$
r=\frac{\tau \pi d_{p} H_{c}}{A_{f} E_{f}}
$$

where $A_{f}$ and $E_{f}$ are the cross-section area and axial Young's modulus of the pin, respectively. $H_{c}$ is the half-thickness of the sandwich composite.

The sudden drop in the traction load and then the further (more gradual) reduction in load with increasing displacement beyond the ultimate load point is due to debonding and pull-out 
of the pin, respectively. The traction load during the pull-out phase arises from friction stress generated between the pin and sandwich composite material. When it is assumed that pin pull-out occurs along the mid-plane of the sandwich material, then the bridging traction load can be calculated using:

$$
P_{\text {pull-out }}(\delta(S))=2\left(H_{s}-S\right) \tau_{f(s)} \pi d_{p}+\left(H_{c}-S\right) \tau_{f(c)} \pi d_{p}
$$

It is assumed for this equation that the pull-out process of the pin is symmetric along the midplane of the core where tensile failure is considered to occur. The first term is the pin pull-out traction load caused by friction between the pin and two face skins while the second term is the traction load generated by sliding friction between the pin and core. $H_{s}$ and $H_{c}$ are the half-thickness values of the skins and core, respectively. $\tau_{f(s)}$ and $\tau_{f(c)}$ are the friction stress between the pin and the face skins and core, respectively. The crack opening displacement during pull-out is a function of the slip length $(S)$ of the pin according to:

$$
\delta(S)=\left[H_{c}-\frac{H_{c}}{r} \ln \left(\frac{\left(H_{c}-S\right) r}{H_{c}}+1\right)\right]\left[1+\frac{\left(H_{c}-S\right) r}{H_{c}}\right]
$$

Equation 5 is valid when the sandwich composite breaks under tensile loading along the midplane of the core, and then the pin pull-out process occurs symmetrically from the two fractured halves of the material. During testing, however, it was observed that this failure mode did not occur, and instead failure occurred at the interface between one of the face skins and foam core, as shown in figure 11 . The majority of the pins were completely pulledout from one face skin whereas pin pull-out did not occur from the other skin. The pins were always completely pulled-out from the face skin containing the chamfered tip (figure 2), and 
presumably failure occurred here because of the lower interfacial contact area between the pin and skin than at the opposite end where the pin was blunt (resulting in higher contact area). When this failure mode occurs and it is assumed that the interfacial friction between the pin and skin is much higher than the pin and core (i.e. $\tau_{f(s)}>>\tau_{f(c)}$ ), then equation 5 can be reduced to:

$$
P_{\text {pull-out }}(\delta(S)) \approx\left(H_{s}-S\right) \tau_{f(s)} \pi d_{p}
$$

Equations 2 and 7 were used to approximate the bridging traction load due to elastic deformation and pull-out of the pin, respectively. Figure 12 compares the calculated bridging traction load curve for a single pin against an experimental curve when the analysis assumes that the pin is aligned in the orthogonal direction in the sandwich composite. The analysis gives a good prediction of the elastic bridging load, although the prediction of the pull-out load with increasing extension is less than the measured pull-out loads.

An important factor influencing the pull-out traction load is the initial misalignment of the pins within the sandwich composite. The analysis (equations 1-7) assumes that the pin is perfectly orthogonal, although figure 3 shows that most of the pins were offset over a range of inclined angles $\left(\phi<12^{\circ}\right)$ from the orthogonal direction. The offset of the pins will induce snubbing, which is the lateral deflection of the pin into the face skin, and this increases the friction stress opposing pin pull-out from the skin. Cartié and Fleck [21] report that the traction load for an inclined pin within a laminate during the pull-out phase is calculated using: 


$$
P(\phi)=\frac{4 \pi d_{p}}{\phi}\left\{\left(h_{s}-S\right) \tau_{f}+z_{o} \tau_{e(s)}\right\}
$$

where $z_{o}$ is the length of the pin deflected into the face skin (and is assumed to be $0.1 h_{s}$ ) and $\tau_{e(s)}$ is the enhanced friction shear stress due to snubbing of the pin within the face skin. Cartié and Fleck [21] suggest that $\tau_{e(s)}$ is between 3 and 10 times higher than $\tau_{f}$ (i.e. the pullout friction stress for a perfectively orthogonal pin).

When the bridging traction load generated by pin pull-out (described mathematically by equation 7) and the effect of snubbing friction stress (equation 8) are combined, then an equation can be derived to analyse for the effect of snubbing on the pull-out traction load of a single pin from one face skin:

$$
\begin{aligned}
& \text { Ppull-out }(\delta(S))=\pi d_{p}\left[\left(\frac{H-S-z_{o}}{\cos \phi}\right) \tau_{f}+z_{0} \tau_{e}\right] \text { for } 0<S<z_{0} \\
& P_{\text {pull-out }}(\delta(S)) \approx\left(H_{s}-S\right) \tau_{f(s)} \pi d_{p} \text { for } S>z_{0} \\
& P_{\text {pull-out }}(\delta(S))=0 \quad \text { for } H=S
\end{aligned}
$$

Equation 9a is valid for the range where the slip length of the pin $(S)$ is between 0 and $z_{0}$, which is the active snubbing zone due to the pin inclination angle and is the pull-out region of the pin within the skin. A schematic of the pin pull-out process is depicted in figure 13 showing the regions of slip length, pin length deflected in the skin, and skin thickness. Once $S$ exceeds the length of $z_{0}$, snubbing is no longer experienced by the pin and equation $9 \mathrm{~b}$ can be used to calculate the traction load in the pull-out phase. When the slip length of the pin reaches $H$, the half-thickness of the skin, the traction load is nullified because the pin has 
completely detached from the skin. Figure 14 shows calculations of the effect of friction snubbing stress on the pull-out traction load for a pin from the face skin of the sandwich composite. It was assumed that the depth of the snubbing zone was $0.1 \mathrm{~mm}$, which is based on measured values for pins within a carbon-epoxy laminate under pure mode II loading [22]. It was also assumed that the pin offset angle was $2.1^{\circ}$, which is the average angle measured for the highest pin content ( $2 \%$ by volume). The different stages of the pin pull-out phase (represented by equations 9a to 9c) are calculated for a range of friction snubbing stresses. Different values of the friction snubbing stress were used in the analysis (i.e. $\tau_{e}$ was assumed to be two, three and five times as high as $\tau_{f}$, which was 6.8MPa). Figure 14 shows that a value in the range of $\tau_{e}=3 \tau_{f}-5 \tau_{f}$ gives a good estimate of the pull-out traction load with increasing crack opening displacement.

\subsection{Pin Bridging Traction in Sandwich Composite Joints}

The fracture process of the z-pinned sandwich joint specimens (shown in figure 8) is more complicated than the failure process of the pin pull-out specimens under pure mode I loading. The fracture process of the z-pinned joint involved multiple damage modes, including centreline splitting along the stiffener, core cracking within the skin, and skin-core interfacial cracking within the face skin. In contrast, the failure of the pin pull-out specimens simply involved fracture along the skin-core interface. Despite these differences, the pin traction loads and traction energies can be used to qualitatively assess the strengthening and toughening effect of pins to sandwich T-joints. Based on the pin traction analysis, the peak fracture load and fracture energy of a pinned sandwich joint should increase with the volume content of pin, and this was proven by experimental testing of the joints. The analysis also revealed that following the onset of pin pull-out in the T-joint specimens, the snubbing effect induced by the pins being at inclined angles provides significant strengthening (high traction 
load) and toughening (high traction energy). The offset of the pin alignment from the orthogonal direction, which was inadvertently caused during manufacture, has a beneficial effect of the joint properties as the pins failed by pull-out.

The pin traction analysis reveals that the structural properties of the sandwich joints under stiffener pull-off loading will increase with, in addition to the volume content of pins, the diameter and inclination angle of the pins and the thickness of the face skins. Therefore, several approaches (pin content, pin diameter, pin angle, skin thickness) can be used in isolation or in combination to strengthened and toughened sandwich T-joints by pinning.

\section{CONCLUSIONS}

Through-thickness reinforcement of the T-shaped sandwich composite joints with pins increased the peak fracture load and fracture energy. The improvement to these properties increased with the volume content of pins, and at the highest (but still modest) content of $2 \%$ that was studied the fracture strength and fracture energy were increased by about $20 \%$ and over $50 \%$, respectively. The fracture load increased with the pin content due to an increase in the traction load generated during elastic stretching and frictional pull-out of the pins. The high amount of energy absorbed by pinned joints during the elastic deformation and pull-out of the pins was partly responsible for the large increase to the fracture energy. The offset of the pins from the perfectly orthogonal direction made a significant contribution to raising the pull-out friction stress and thereby the fracture energy to the joint. Mechanics-based analysis revealed that other parameters that can increase the fracture resistance of the joint are increasing pin diameter and skin thickness, although this remains to be verified by experimental testing. The improvements to the structural properties of the joint due to pinning was accompanied by a change to the fracture mode; from bond-line delamination cracking for 
the unpinned joint to skin fracture (due to suppression of bond-line cracks) in the pinned joints, which demonstrates the high toughening effect of pin reinforcement.

\section{Acknowledgements}

The authors thank Mr. Bob Ryan and Mr. Peter Tkatchyk (RMIT University) for technical assistance in the manufacture and testing of the sandwich specimens. The first author also acknowledges financial support provided by the Australian Postgraduate Award and the Cooperative Research Centre for Advanced Composite Structures.

\section{References}

1. Guo S, Morishima R. Numerical analysis and experiment of composite sandwich Tjoints subjected to pulling load. Comp. Struct., 2011;94:229-238.

2. Theotokoglou EE, Moan T. Experimental and numerical study of composite T-joints. J Comp Mat, 1996;30:190-209.

3. Turuga UVRS, Sun CT. Failure modes and load transfer in sandwich T-joints. J. Sand. Struct. \& Mat., 2000:2:225-245.

4. Shenoi RA, Read PJCL, Jackson CL. Influence of joint geometry and load regimes on sandwich tee joint behaviour. J Rein Plas \& Comp, 1998;17:725-740.

5. Rugg KL, Cox BN, Massabò R. Mixed mode delamination of polymer composite laminates reinforced through the thickness by z-fibres, Comp, 2002;33:177-190.

6. Cartié DDR, Dell’ Anno G, Poulin E, Partridge, IK. 3D reinforcement of stiffener-to-skin T-joints by z-pinning and tufting, Eng Fract Mech, 2006;73:2532-2540.

7. Chang P, Mouritz AP, Cox BN. Tensile properties and failure mechanisms of z-pinned composite lap joints, Comp Sci \& Tech, 2006;66:2163-2176. 
8. Grassi M, Cox B, Zhang X. Simulation of pin-reinforced single-lap composite joints, Comp Sci \& Tech, 2006;66:1623-1638.

9. Byrd LW, Birman V. Effectiveness of z-pins in preventing delamination of co-cured composite joints on the example of a double cantilever test, Comp, 2006;37B:365-378.

10. Chang P, Mouritz AP, Cox BN. Elevated temperature of pinned composite laminate joints. J Comp Mats, 2008;42:741-769.

11. Koh TM, Feih S, Mouritz AP. Experimental determination of the structural properties and strengthening mechanisms of z-pinned composite T-joints, Comp Struct, 2011;93:2222-30.

12. Park Y-B, Lee B-H, Kweon J-H, Choi J-H, Choi I-H. The strength of composite bonded T-joints transversely reinforced by carbon pins, Comp Struct, 2012;94:625-634.

13. Toral Vazquez J, Castanie B, Barrau J-J. Swiergiel N. Multi-level analysis of low-cost zpinned composite joints. Part 2: joint behaviour’, Comp, 42A;2011:2082-2092.

14. Koh TM, Isa MD, Chang P, Mouritz AP. Improving the structural properties and damage tolerance of composite joints using z-pins, J Comp Mat (in press).

15. Mouritz A P. Review of z-pinned composite laminates. Comp. 2007;38A:2383-2397.

16. Chang P, Mouritz AP, Cox BN. Properties and failure mechanisms of z-pinned laminates in monotonic and cyclic tension, Comp, 2006;37A:1501-1513.

17. Dai SC, Yan W, Liu HY, Mai YW. Experimental study on z-pin bridging law by pullout test. Comp Sci Tech. 2004;64:2451-2457.

18. Zhang A, Liu H, Mouritz AP, Mai Y. Experimental study and computer simulation on the degradation of z-pin reinforcemen under cyclic fatigue. Comp. 2008;39A:406-14.

19. Koh TM, Feih S, Mouritz AP. Strengthening mechanics of thin and thick composite Tjoints reinforced with z-pins, Comp. A, (in press). 
20. Jain LK, Wetherhold RC. The effect of fibre extensibility on the fracture toughness of short fibre/brittle matrix composites. App Mech Reviews. 1992;45:377-89.

21. Cartié DDR, Fleck NA. The effect of pin reinforcement upon the through-thickness compressive strength of foam-cored sandwich panels, Comp Sci Tech, 2003;63:24012409.

22. Nanayakkarra A, Feih S, Mouritz AP. Experimental analysis of the through-thickness compression properties of z-pinned sandwich composites, Comp 2011;42A:1673-1680.

23. Chang P. Mechanical Properties and Failure Mechanisms of Z-Pinned Composites, PhD Thesis, RMIT University, 2006.

24. Cartié DDR, Cox BN, Fleck NA. Mechanisms of crack bridging by composite and metallic rods. Composites Part A: Applied Science and Manufacturing. 2004;35(11):1325-36. 


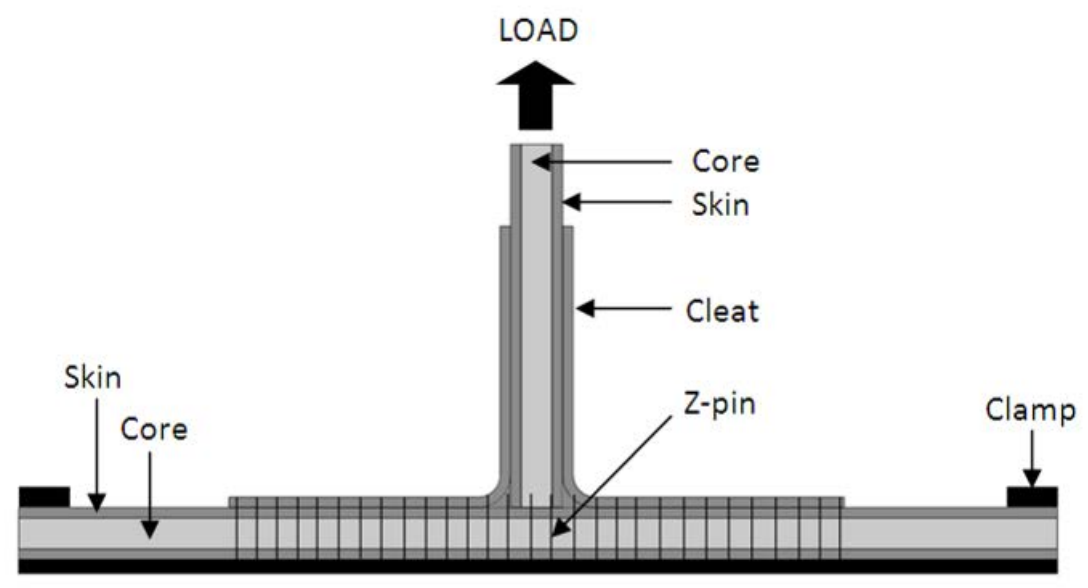

(a)

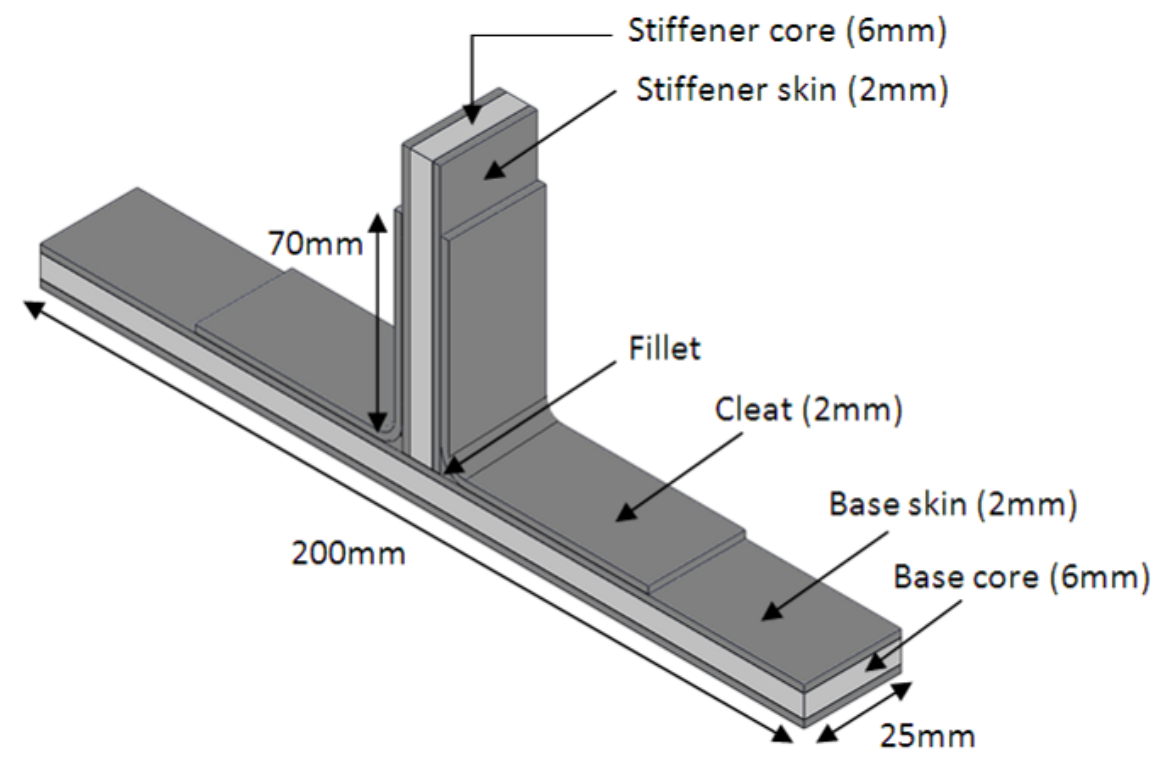

(b)

Figure 1. Schematic of the design and dimensions of the sandwich T-joint used in the structural pull-off test. The region that was reinforced with z-pins and the direction of applied loading is indicated in (a). 


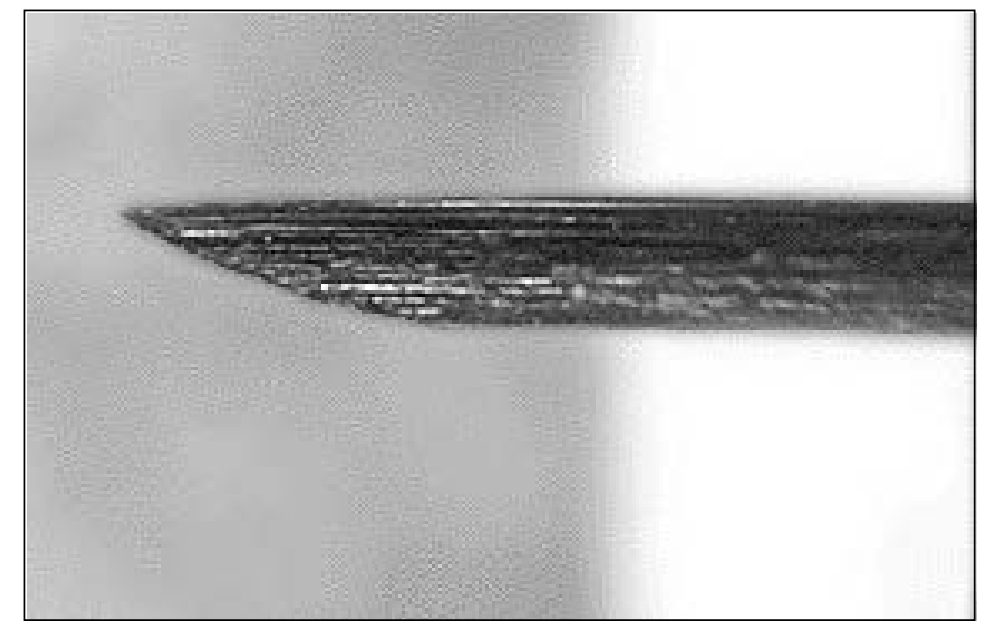

(a)

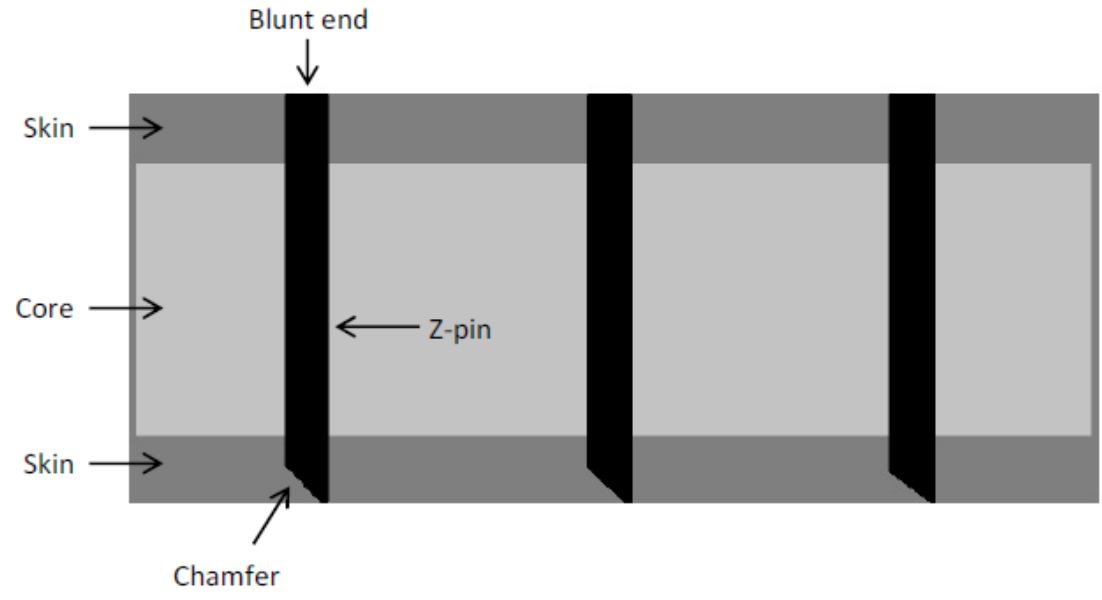

(b)

Figure 2. (a) Chamfer to the pin tip. (b) The pins in the sandwich composite were all chamfered within one face skin and blunt in the other skin. 


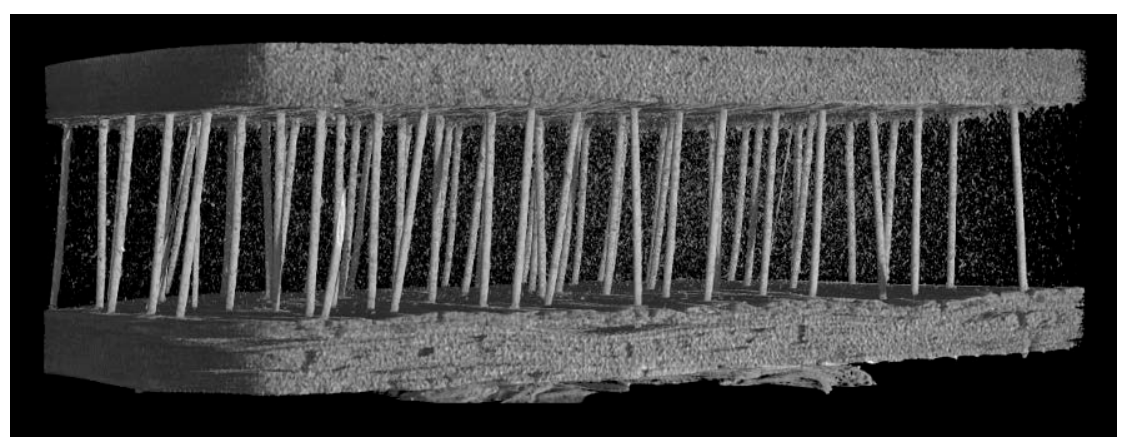

(a)

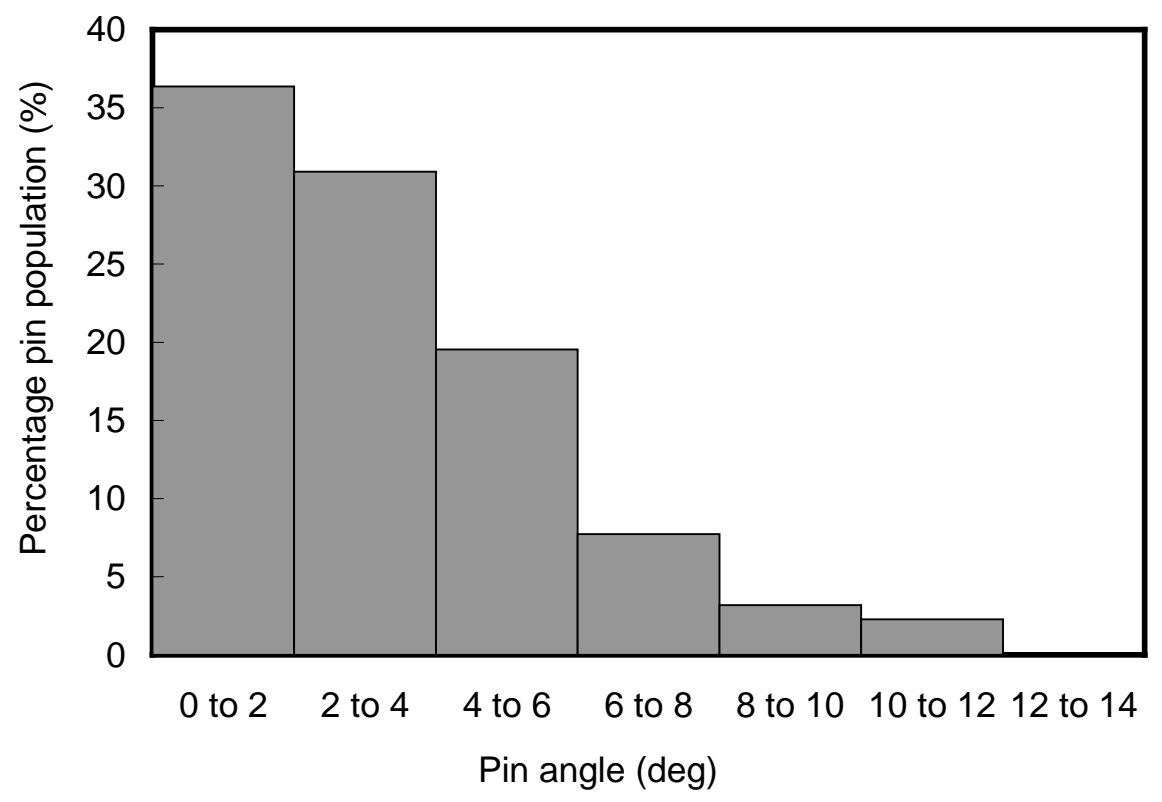

(b)

Figure 3. (a) X-ray computed tomography image of a pinned sandwich composite specimen showing that the pins are inclined at various angles. The foam core has been digitally removed from the image to reveal the pins. (b) Histograms of pin population against inclination angle for the sandwich material. From [22]. 

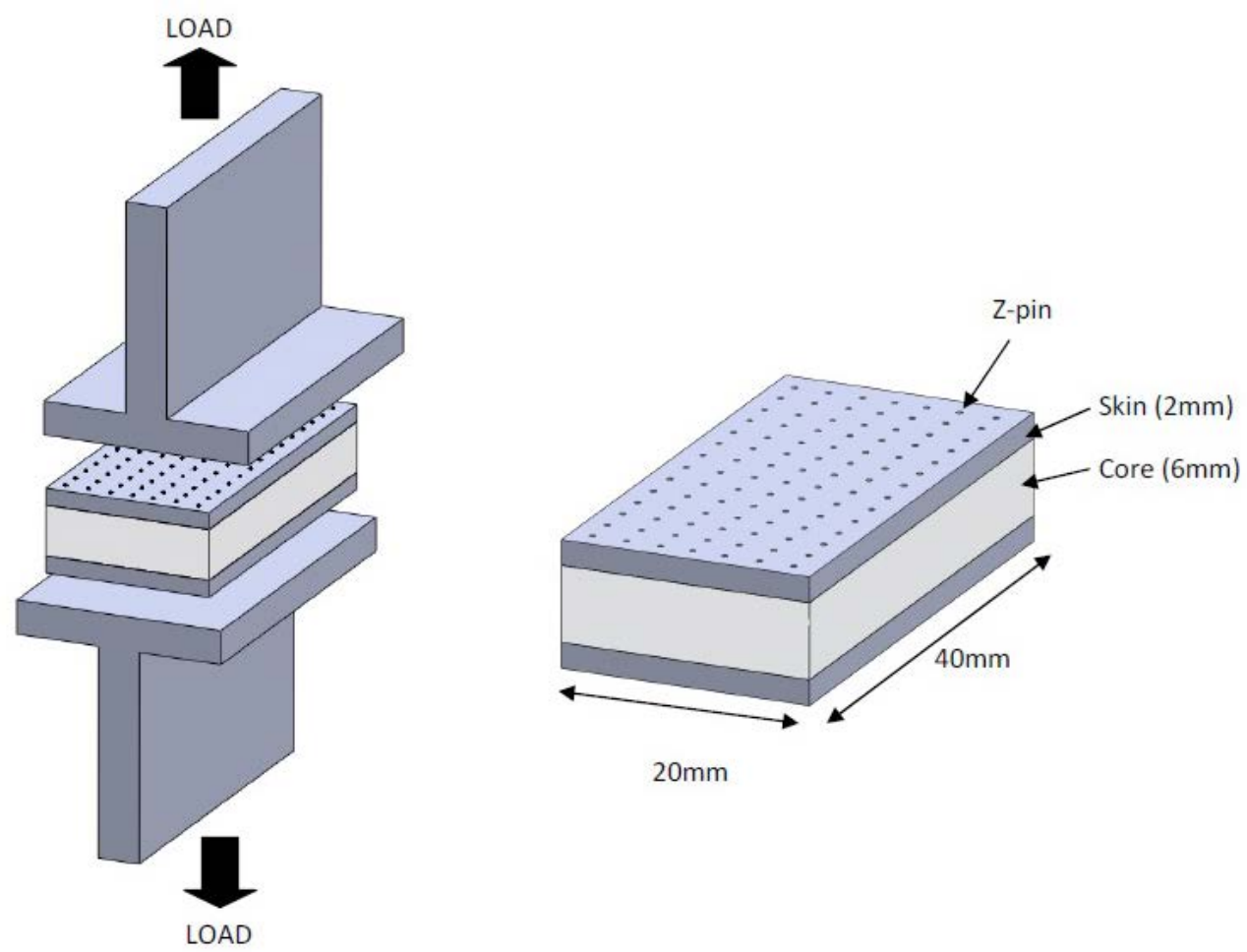

Figure 4. Pin pull-out tests on flat sandwich panels.

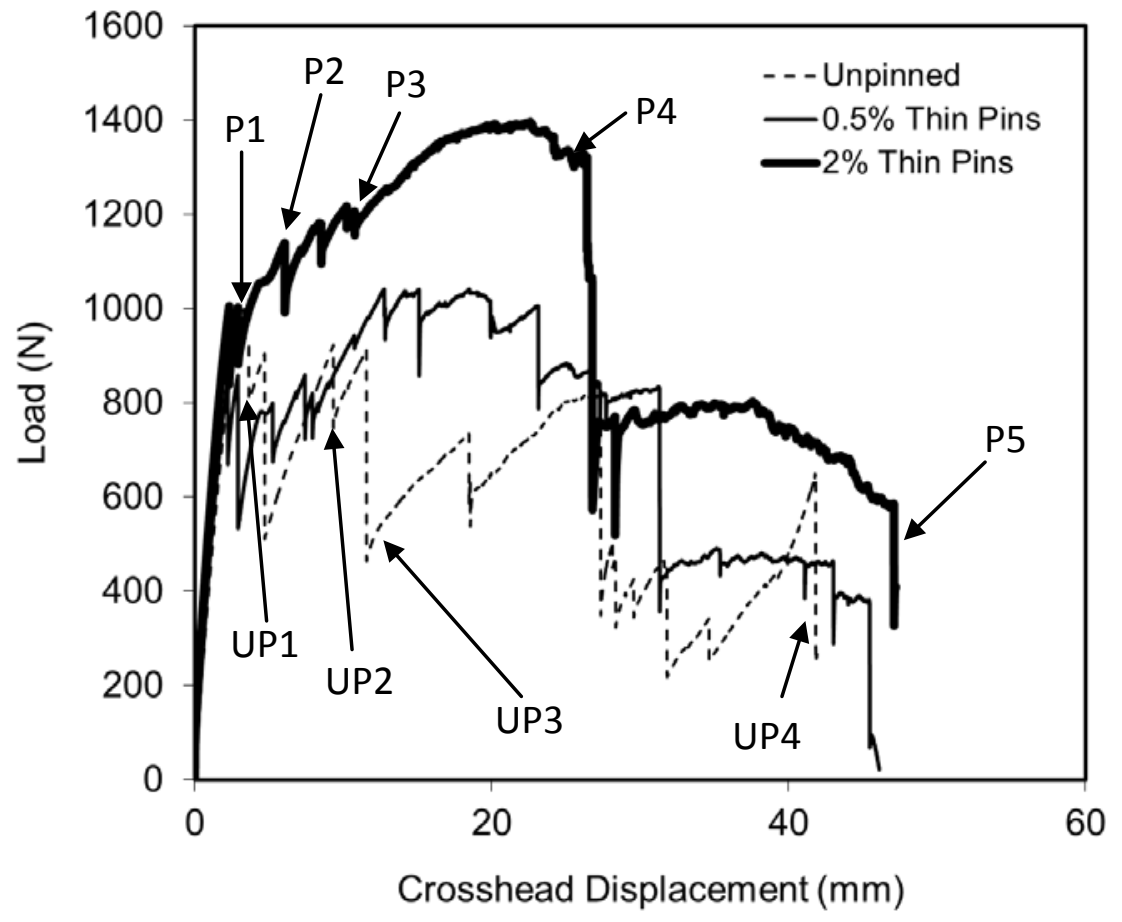

Figure 5. Applied load-displacement curves for unpinned and pinned sandwich T-joints. 


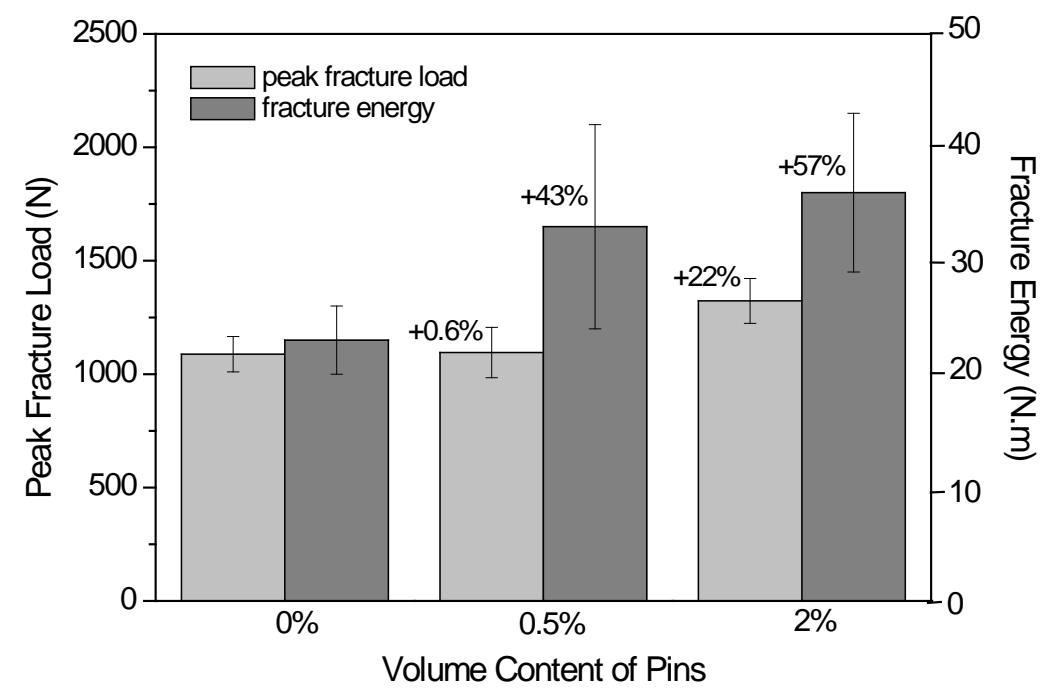

Figure 6. Effect of pin content on the peak fracture and fracture energy of the sandwich Tjoint. The percentage values show the increase to the fracture properties of the pinned joints relative to the unpinned (control) joint.

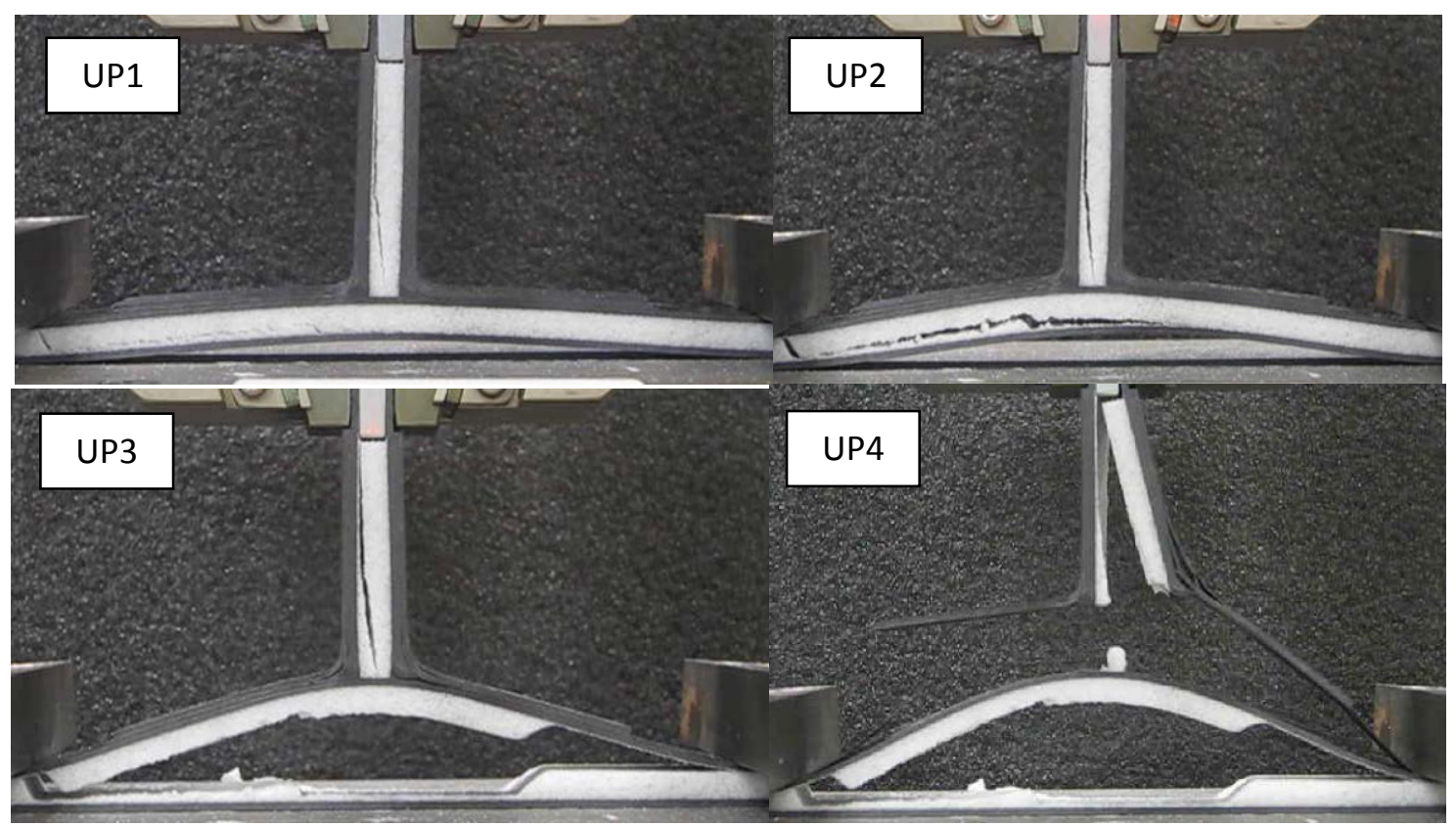

Figure 7. Failure of unpinned sandwich T-joint. The points labelled UP1 - UP4 are indicated in the load-displacement curve in figure 5 when the photos were taken. 


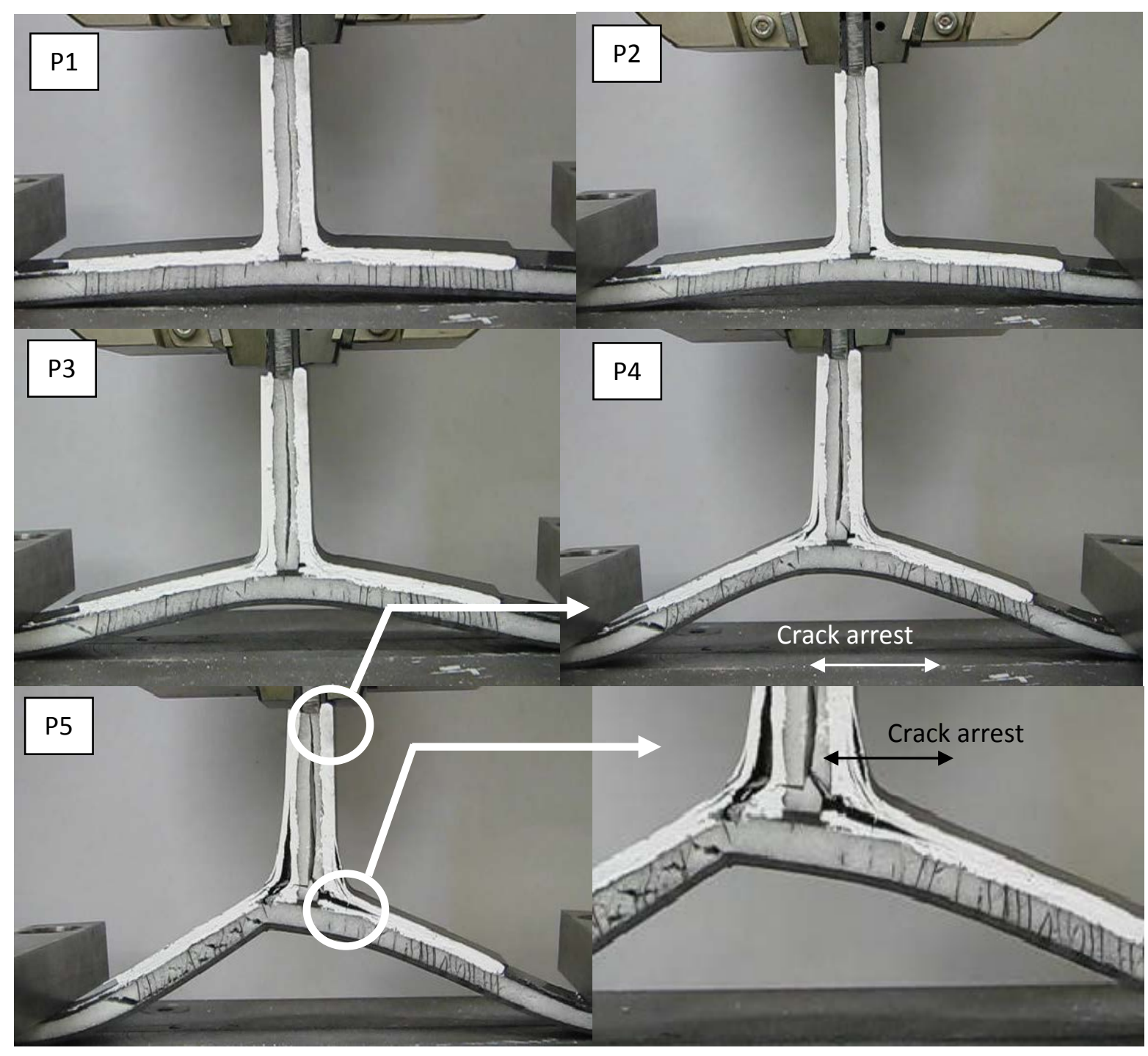

Figure 8. Failure of 2\% pinned sandwich T-joint. The points labelled P1 - P5 are indicated in the load-displacement curve in figure 5 when the photos were taken. 


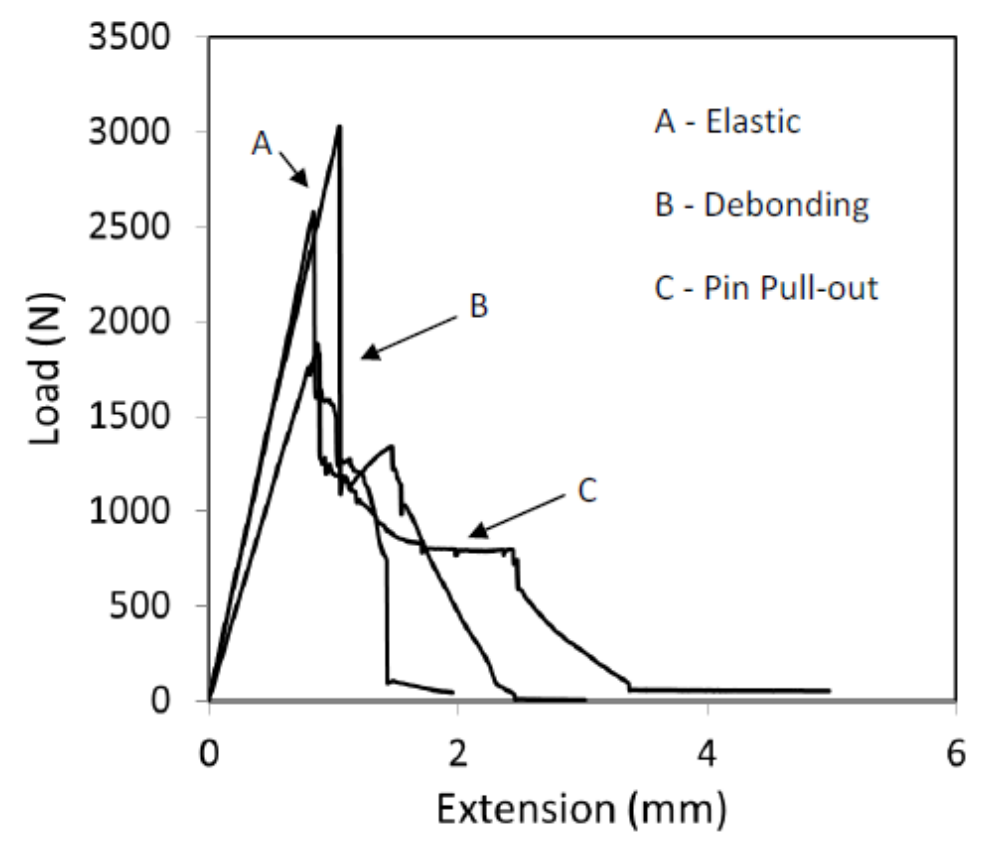

Figure 9. Load-extension curves for a single pin within three samples of the sandwich composite tested under through-thickness tensile loading. The three stages of pin response to the loading are indicated.

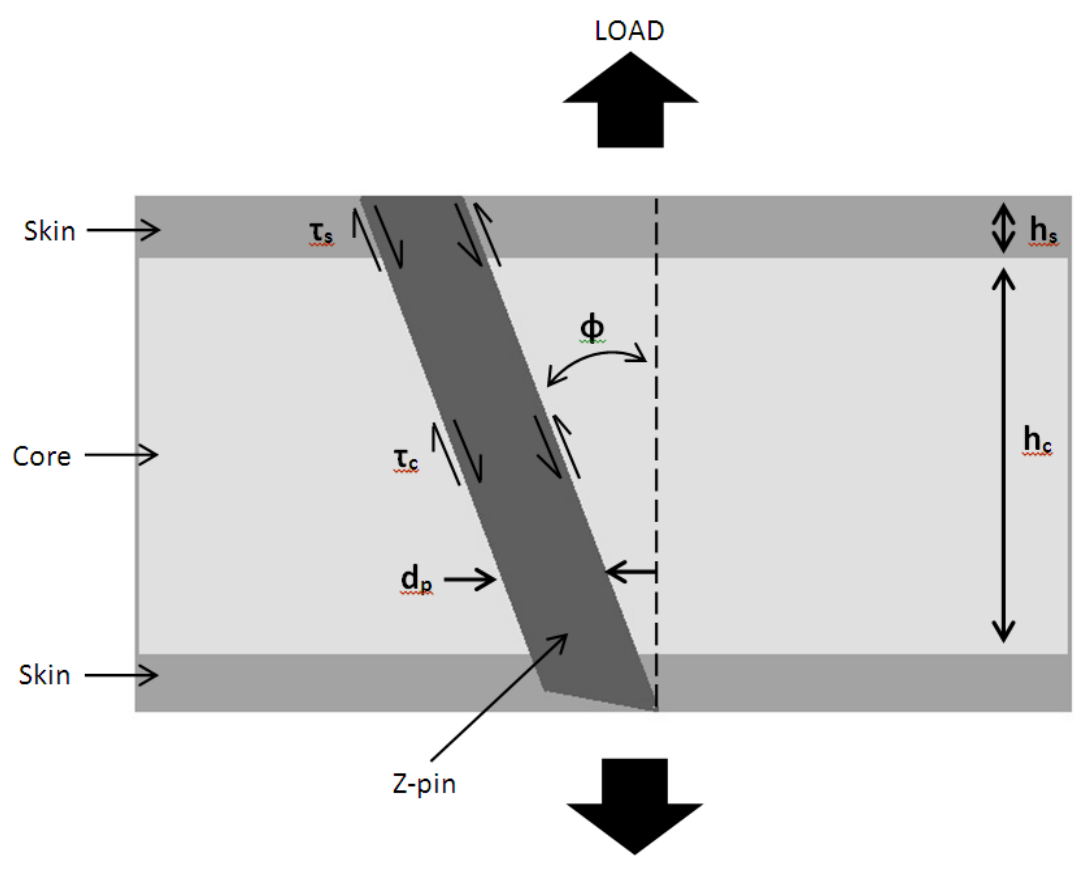

Figure 10. Traction stresses acting along the pin-sandwich composite interface under a through-thickness tensile load. The pin is inclined from the orthogonal direction by the angle $\phi$. 


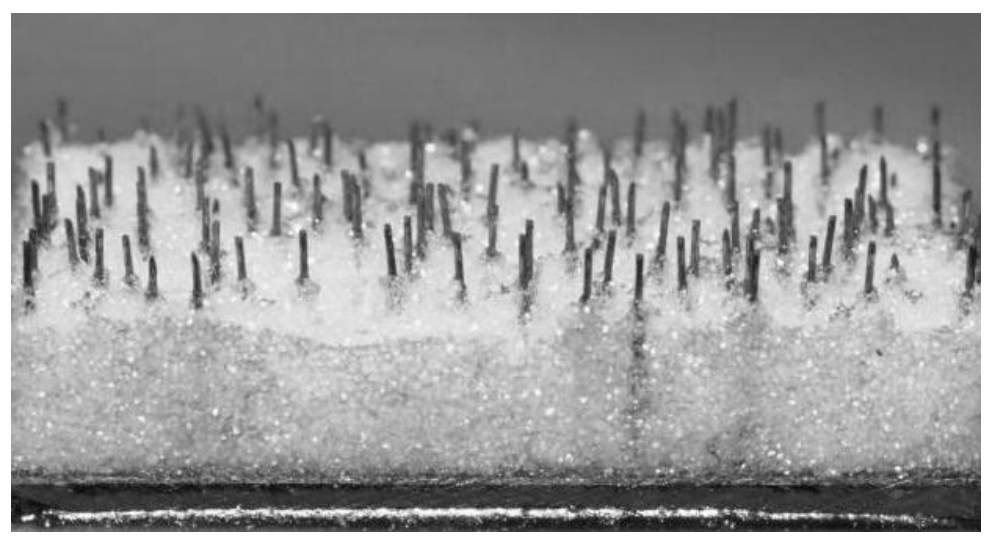

(a)

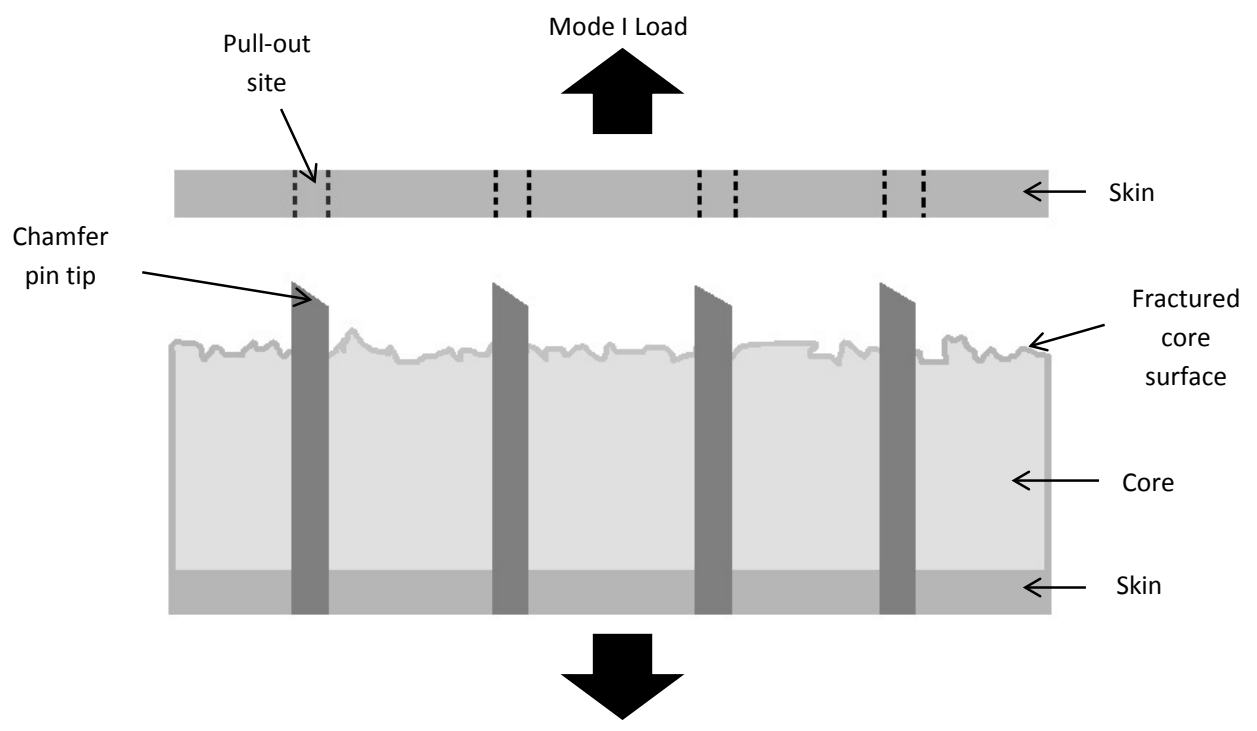

(b)

Figure 11. (a) Pin pull-out specimen which failed along the skin-core interface resulting in pin pull-out from the face skin. Shown are the z-pins remaining in the core and lower face skin after the upper skin has been pulled-off. (b) Schematic of the pin pull-out process from the sandwich composite. 


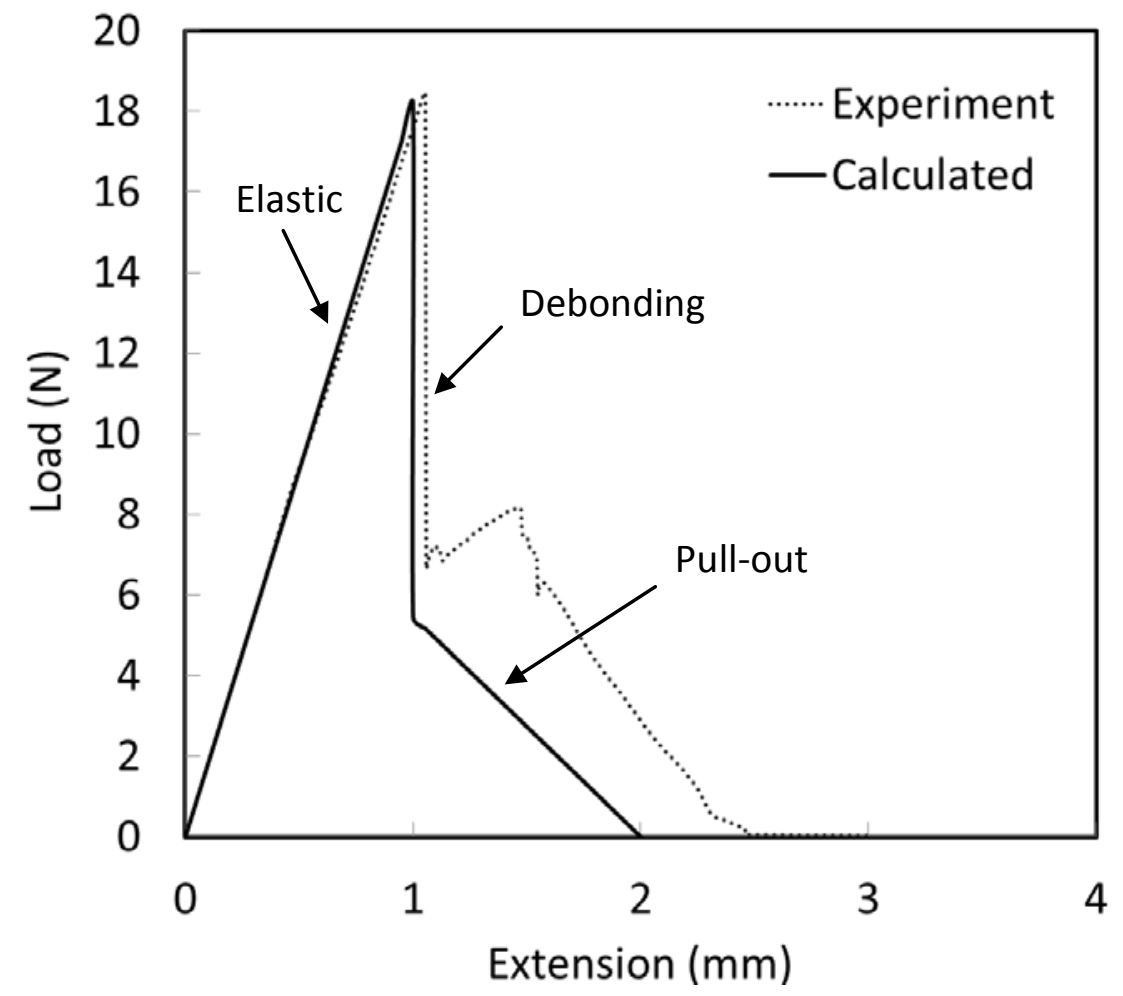

Figure 12. Comparison of the calculated and measured pin traction load-extension curve. The calculated curve assumes that the pin is perfectly orthogonal. Note the calculated curve is less than the measured curve during the pin pull-out phase.

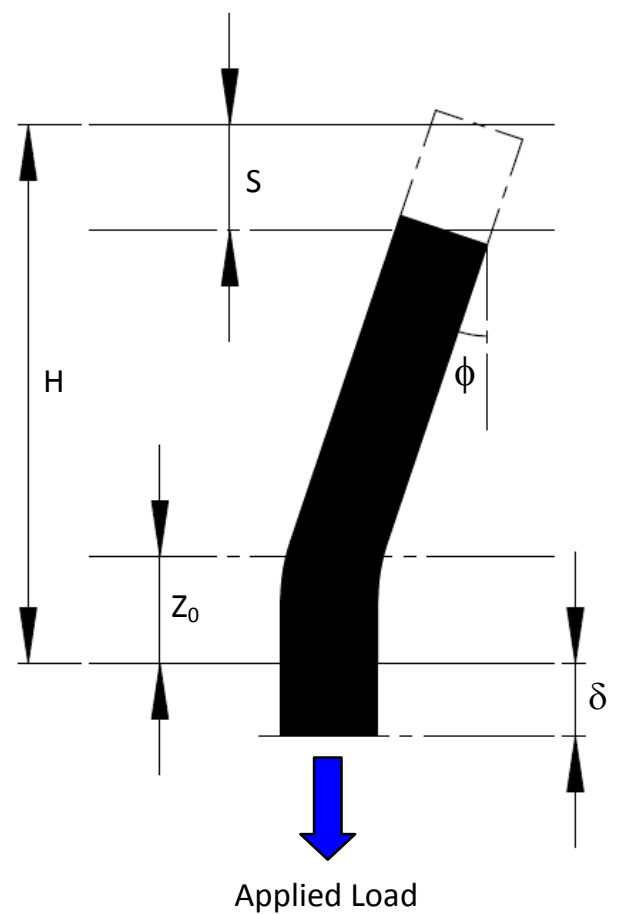

Figure 13. Schematic of pull-out process for a pin inclined at an angle $(\phi)$ from the orthogonal direction. Adapted from Cartié et al. [24]. 


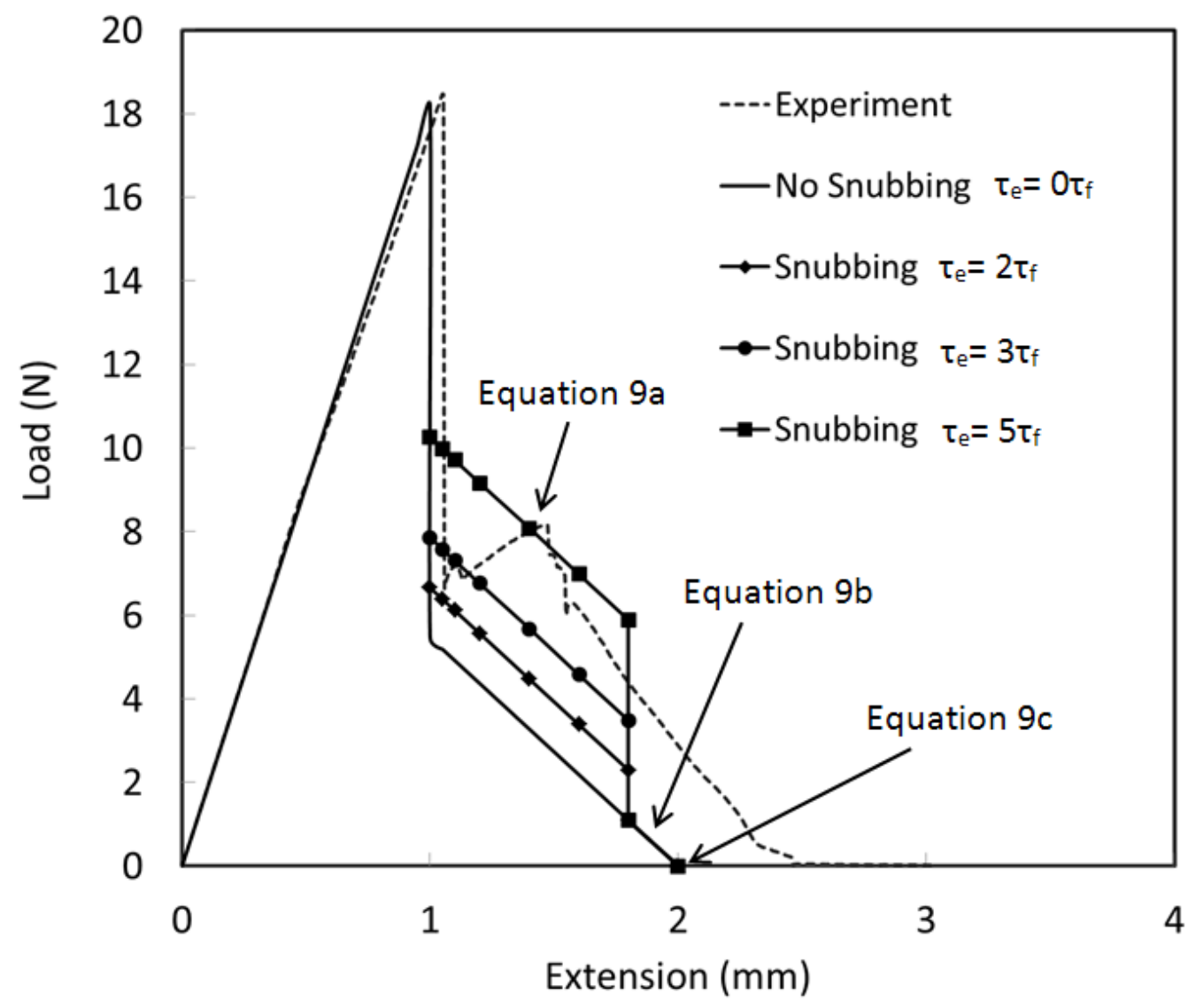

Figure 14. Comparison of the calculated pin traction load-extension curves and a measured curve. The calculated curves consider different magnifications of the enhance friction (snubbing) stress caused by offset of the pin from the orthogonal direction. 